\title{
Characterization of a New Simian T-Lymphotropic Virus Type 1 (STLV-1) in a Wild Living Chimpanzee (Pan troglodytes verus) from Ivory Coast: Evidence of a New STLV-1 Group?
}

\author{
FABIAN H. LEENDERTZ, ${ }^{1-3}$ CHRISTOPHE BOESCH,${ }^{2}$ SANDRA JUNGLEN,${ }^{1}$ GEORG PAULI, ${ }^{1}$ \\ and HEINZ ELLERBROK ${ }^{1}$
}

\begin{abstract}
A new strain of simian T-lymphotropic virus type 1 in blood samples from a chimpanzee that lived in the tropical rainforest of Ivory Coast is described. The sequence obtained from the long terminal repeat region of the genome is significantly divergent from all known human and nonhuman primate T-lymphotropic virus type 1 strains (96.3\% homology to the closest related strains from Central African subtype B) and clusters with none of the established clades. The tax sequences reveal two sequence differences that seem to be unique as they are not found in any of the HTLV-1 or STLV-1 tax sequences from the public databases.
\end{abstract}

$S^{3}$ Mian T-LyMPhotropic VIRUS TYPE 1 (STLV-1) and human T-lymphotropic virus type 1 (HTLV-1) are closely related. STLVs have been found in numerous nonhuman primate species. ${ }^{1-5}$ STLV-1 and HTLV-1 nucleotide sequence homologies range from 85 to $98 \%$. However, some of the most closely related STLV-1 and HTLV-1 strains are less divergent than are HTLV-1 subtypes compared with each other. ${ }^{5}$ These observations suggest multiple interspecies transmissions, both among different primate species and between primates and humans. ${ }^{1,5-9}$

In this study we present sequence data for an STLV strain isolated from a chimpanzee (Pan troglodytes verus) living in its natural habitat, the tropical rainforest of Africa. ${ }^{10}$ The chimpanzee, called Leo, was the alpha male of a study group of freeranging chimpanzees living under human observation since 1998 in the Taï National Park, Ivory Coast. Leo was about 19 years old when he died a sudden death on February 14, 2002. So far, the definitive reason for his death has remained unexplained. Full blood was taken during necropsy, placed immediately in aliquots in liquid nitrogen, and stored at $\leq-70^{\circ} \mathrm{C}$ until further use.

The blood sample was analyzed for HTLV-specific antibodies in an enzyme-linked immunosorbent assay (HTLV-1/2 ELISA; Murex Biotech, Dartford, UK). The positive ELISA result was confirmed by Western blotting (HTLV blot version
2.4; Genelabs Diagnostics, Singapore). The reaction profile was indistinguishable from the HTLV-1-positive control serum, with strong reactivities against p19, p24, gp46, rgp46-I, and GD21, suggesting that the chimpanzee was infected with an HTLV-1-related virus.

Aliquots of the frozen blood were thawed and DNA was extracted, using a QIAamp DNA blood minikit (Qiagen, Hilden, Germany). The absence of PCR inhibitors from the DNA sample was verified by a real-time PCR (TaqMan PCR) assay based on the sequence of human endogenous retrovirus R (HERV-R, data not shown).

The DNA sample was further analyzed for the presence of HTLV-like proviral DNA, using HTLV-1 tax- and pol-specific real-time PCR assays (details of the method are described elsewhere). For tax PCR primers SK43 and SK44, and for pol PCR primers SK110 and SK111, ${ }^{11}$ were combined with sequencespecific fluorescently labeled TaqMan probes. For each reaction $500 \mathrm{ng}$ of total DNA was used. Each assay was run in duplicate, including appropriate positive and negative controls. Using standards with defined copy numbers of the target DNA, 50 proviral copies in the PCR assay was determined for both the $p o l$ and the tax region. The number of STLV-infected cells could be calculated as approximately 1 in 1000 cells.

In three independent PCRs starting from two independent DNA preparations, $\operatorname{tax}$ PCR product was generated with primers

${ }^{1}$ Retrovirology, Robert Koch Institut, 13353 Berlin, Germany.

${ }^{2}$ Max Planck Institut for Evolutionary Anthropology, 04103 Leipzig, Germany.

${ }^{3}$ Institute for Parasitology and International Animal Health, Free University of Berlin, Berlin, Germany. 
SK43 and SK44. ${ }^{11}$ The 160 -bp product was analyzed by agarose gel electrophoresis and the sequence was determined on both strands, using SK43 and SK44 as sequencing primers. The amplimers were sequenced with an ABI Prism BigDye terminator cycle sequencing Ready Reaction kit (PE Applied Biosystems, Oak Brook, IL).

The 118-bp tax sequence internal to the primers, which is usually well conserved among HTLV-1 and STLV-1 isolates, revealed two sequence differences compared with the HTLV1 ATK prototype (accession number J02029): an A for a G at position 7433 and a $\mathrm{T}$ for a $\mathrm{C}$ at position 7482 . The two sub- stitutions seemed to be unique as they were not present in any of the published HTLV-1 or STLV-1 tax sequences. To further characterize this isolate, the $3^{\prime}$ region of the STLV genome was sequenced and investigated by phylogenetic tree analysis.

To amplify tax and the long terminal repeat (LTR) region, we used primer sequences derived from HTLV-1 ATK. ${ }^{12}$ Primers SK43 ${ }^{11}$ and LTR R2 ${ }^{13}$ were used in the first PCR to amplify a $1.6-\mathrm{kb}$ fragment covering tax and rex as well as the 3' LTR (nucleotide positions 7357 to 9036 in ATK). Because in agarose gel electrophoresis no clear PCR fragment of the expected size could be identified after first-round PCR, primers

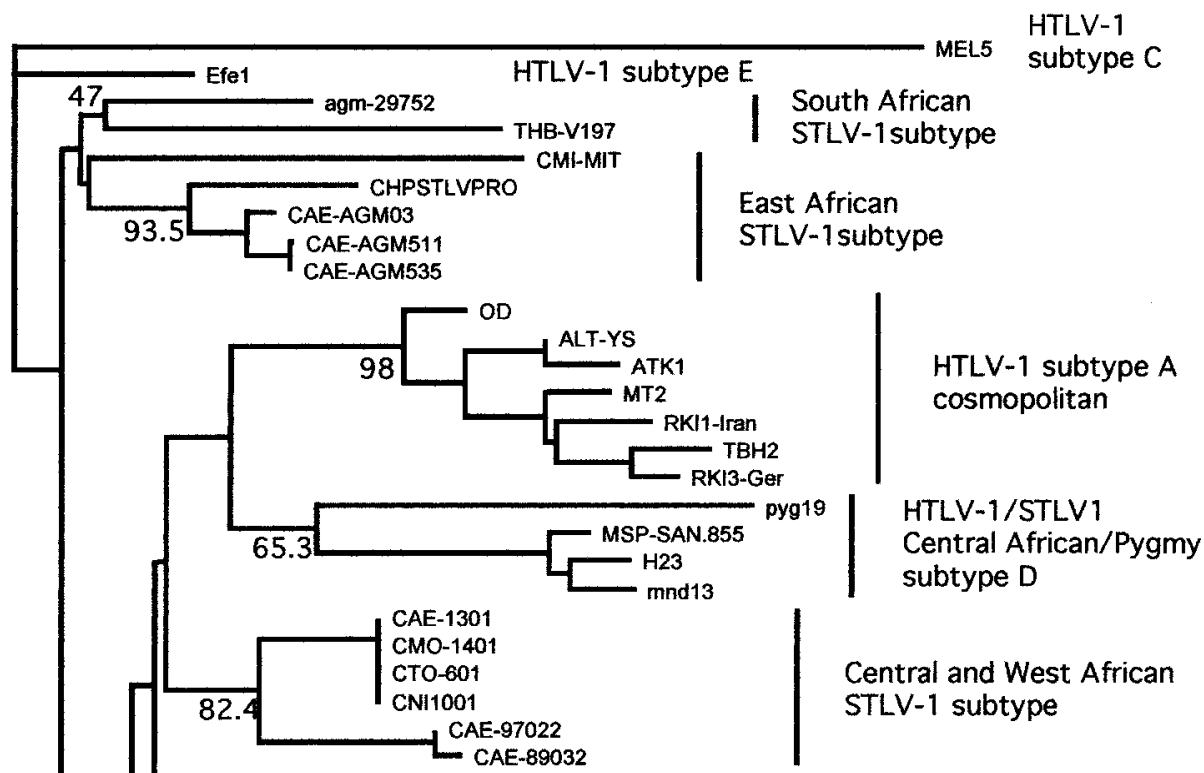

Baboon STLV-1 subtype

African HTLV-1/STLV-1 subtype F
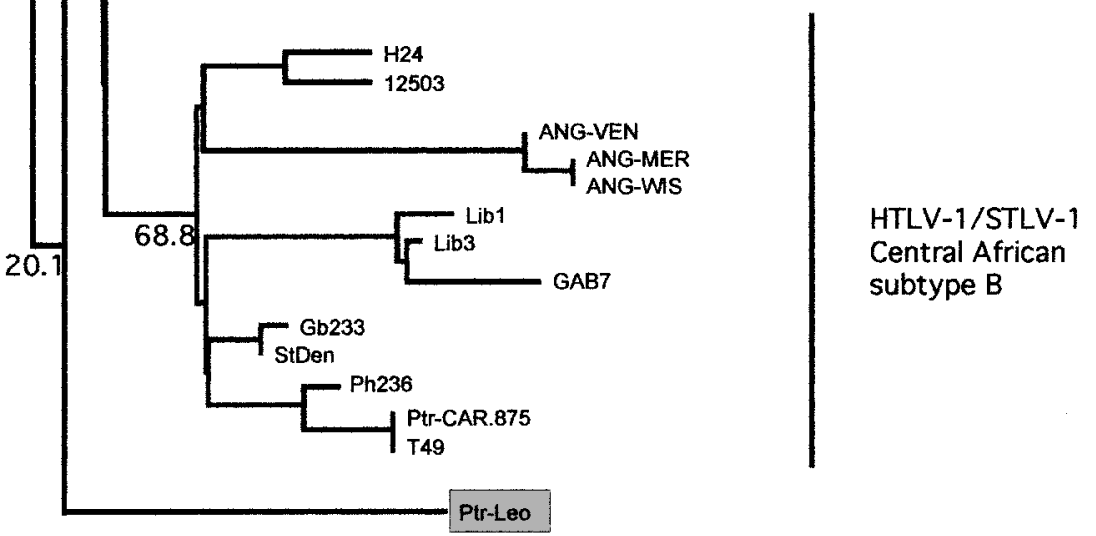

FIG. 1. A rooted phylogenetic tree, generated by the neighbor-joining method and based on a 665-bp LTR fragment corresponding to nucleotide positions 8331 to 8995 of the ATK sequence. HTLV-1 subtype isolate Mel 5 was used as an outgroup. The tree was statistically evaluated in a bootstrap analysis with 1000 bootstraps. Bootstrap values for the major branching points are given as percent values. The different HTLV-1 subtypes are indicated. The Ptr-Leo isolate is highlighted in a shaded box. 
SK43 and R6 (AGTTCAGGAGGCACCACAGGCG) covering nucleotides 7357 to 8683 and primers S10 (GGCCCTAATAATTCTACCCG) and R2 covering nucleotides 7928 to 9036 were used in seminested PCRs to generate two largely overlapping fragments. PCR conditions for first-round PCR and for seminested PCRs were as follows: 1 cycle of 3 min at $94^{\circ} \mathrm{C}$; 40 cycles of $30 \mathrm{sec}$ at $94^{\circ} \mathrm{C}, 30 \mathrm{sec}$ at $58^{\circ} \mathrm{C}$; and $3 \mathrm{~min} 72^{\circ} \mathrm{C}$. All reactions were performed with Combi Pol (InVitek, Berlin, Germany), an enzyme mix with proofreading activity. Both seminested PCRs yielded single bands of the expected size. The PCR fragments were cut out of the agarose gel and DNA was extracted with a Qiagen gel extraction kit. Using the PCR primers and additional internal primers derived from the HTLV1 ATK sequence, a 1.6-kbp sequence of the isolate, termed PtrLeo, was determined for both strands (submitted to the public databases, accession number AF539747). To avoid sequence alterations due to Taq polymerase errors, the sequence was confirmed by repeating both seminested PCRs, starting with an independent aliquot of genomic DNA. The $\operatorname{tax} / \mathrm{LTR}$ sequence from the isolate Ptr-Leo revealed 76 nucleotide differences compared with HTLV-1 ATK (4.7\% nucleotide divergence), whereas the LTR region alone was 5.8\% divergent. For the LTR region the closest homologies found were 96.3 and $96.2 \%$ for isolates from HTLV-1/STLV-1 Central African subtype B. Several other sequences from this subtype, but also sequences from the Central and West African STLV-1 subtype and from the HTLV-1 subtype E isolate Efe1, showed 93.1\% homology.

A 665-bp LTR fragment from Ptr-Leo, corresponding to nucleotides 8331 to 8995 of the ATK sequence, was aligned with HTLV-1 and STLV-1 sequences from the public databases and a phylogenetic tree was constructed, using the neighbor-joining method. ${ }^{14}$ Ptr-Leo did not cluster with the established clades (Fig. 1). However, in a bootstrap analysis using 1000 replicates the branch for Ptr-Leo displayed only low-level statistical significance $(20.1 \%)$. Using the DNA maximum parsimony method, the configuration of the tree was similar, but again the branch for Ptr-Leo was not well supported (data not shown).

Our study demonstrates the presence of STLV-1 in a freeranging chimpanzee living in its natural habitat, the tropical rainforest of Ivory Coast, West Africa. Cross-species infection from primates originating from outside of the habitat can be excluded.

Sequence analyses of $\operatorname{tax}$ and the LTR region of the presented STLV-1 strain showed that the sequences are distinct from all known chimpanzee, simian, or human T-lymphotropic virus type 1 sequences and do not belong to any PTLV-1 phylogenetic clusters described.

The finding of this new STLV-1 strain suggests that the biodiversity of STLV in free-ranging primates in their natural habitats is far from elucidated. Knowledge about the prevalence and circulation of STLV-1 among free-ranging primates may help to understand the evolution of this virus. Further analyses will be necessary to show the prevalence of STLV infections in the primate populations that have been under observation for several years. ${ }^{10}$ Molecular analyses of further samples from additional primates will provide data on the distribution and phylogenetic variation of this newly found STLV-1 strain within the same and other chimpanzee groups as well as among other primates living in the same ecosystem.

\section{ACKNOWLEDGMENTS}

We thank the Ivorian authorities for long-term support, especially the Ministry of the Environment and Forests as well as the Ministry of Research, the directorship of the Taï National Park, and the Swiss Research Center in Abidjan. For skillful technical support we want to thank S. Neumann, H. v. Spreckelsen, S. Pociuli, H. Emmel, A. Sioblo, and T. Deschner. For the field work F.H. Leendertz as awarded a grant from the German Academic Exchange Service (DAAD).

\section{SEQUENCE DATA}

Accession numbers: agm-29752 (AF 061847), ALT-YS (U19949), ANG-MER (AY026858.1), ANG-VEN (AY026857.1), ANG-WIS (AY026856.1), ATK1 (J02029), CAE-AGM511 (AY026847.1), CAE-AGM535 (AY026846.1), CAE-89032 (AY026851.1), CAE-97022 (AY026850.1), CAE-AGM03 (AY026848.1), CAE-1301 (AY026852.1), CAG-DJA.853 (AF384872), CHPSTLVPRO (M33064), CMI-MIT (AY 026845), CMO-1401 (AY026853.1), CNI-1001 (AY026854.1), CTO-601 (AY026855.1), Efe1 (Y17014.1), GAB7 (L76311.1), Gb233 (D23692), H23 (L76312), H24 (L76308.1), Lib1 (Y17016.1), Lib2 (Y17017), Lib3 (Y17018.1), MEL5 (L02534), mnd9 (AF045932), mnd13 (AF045933), MSP-SAN.855 (AF384870), MT2 (L03561), OD (U12805), PAN-614 (AY026844.1), PAN-622 (AY026843.1), PAN-623 (AY026842.1), PH236 (L76307.1), PtrA26 (U86376), Ptr-CAR.875 (AF384871.1), Pyg19 (L76310), RKI1-Iran (AF003010), RKI3-Ger (AF042071.1), StDen (L76306.1), TBH2 (L76025), T49 (L76305), 12503 (L76309.1).

\section{REFERENCES}

1. Voevodin AF, Johnson BK, Samilchuk EI, et al.: Phylogenetic analysis of simian T-lymphotropic virus type I (STLV-I) in common chimpanzees (Pan troglodytes): Evidence for interspecies transmission of the virus between chimpanzees and humans in Central Africa. Virology 1997;238:212-220.

2. Saksena NK, Herve V, Durand JP, et al.: Seroepidemiologic, molecular, and phylogenetic analyses of simian T-cell leukemia viruses (STLV-I) from various naturally infected monkey species from central and western Africa. Virology 1994;198:297-310.

3. Nerrienet E, Meertens L, Kfutwah A, Foupouapouognigni Y, and Gessain A: Molecular epidemiology of simian T-lymphotropic virus (STLV) in wild-caught monkeys and apes from Cameroon: A new STLV-1, related to human T-lymphotropic virus subtype F, in a Cercocebus agilis. J Gen Virol 2001;82:2973-2977.

4. Mahieux R, Chappey C, Meertens L, Mauclere P, Lewis J, and Gessain A: Molecular characterization and phylogenetic analyses of a new simian $\mathrm{T}$ cell lymphotropic virus type 1 in a wild-caught African baboon (Papio anubis) with an indeterminate STLV type 2-like serology. AIDS Res Hum Retroviruses 2000;16: 2043-2048.

5. Koralnik IJ, Boeri E, Saxinger WC, et al.: Phylogenetic associations of human and simian T-cell leukemia/lymphotropic virus type I strains: Evidence for interspecies transmission. J Virol 1994;68: 2693-2707.

6. Liu HF, Goubau P, Van Brussel M, et al.: The three human T-lymphotropic virus type I subtypes arose from three geographically distinct simian reservoirs. J Gen Virol 1996;77:359-368. 
7. Crandall KA: Multiple interspecies transmissions of human and simian T-cell leukemia/lymphoma virus type I sequences. Mol Biol Evol 1996;13:115-131.

8. Voevodin A, Samilchuk E, Schatzl H, Boeri E, and Franchini G: Interspecies transmission of macaque simian T-cell leukemia/lymphoma virus type 1 in baboons resulted in an outbreak of malignant lymphoma. J Virol 1996;70:1633-1639.

9. Salemi M, Desmyter J, and Vandamme AM: Tempo and mode of human and simian T-lymphotropic virus (HTLV/STLV) evolution revealed by analysis of full-genome sequences. Mol Biol Evol 2000; 17:374-386.

10. Boesch $\mathrm{C}$ and Boesch-Achermann H: Hunting behaviour in wild chimpanzees. In: The Chimpanzees of the Tai Forest: Behavioural Ecology and Evolution. Oxford University Press, Oxford, 2000, pp. 159-162.

11. Kwok S, Ehrlich G, Poiesz B, Kalish R, and Sninsky JJ: Enzymatic amplification of HTLV-1 viral sequences from peripheral blood mononuclear cells and infected tissues. Blood 1988;72:1117-1123.
12. Seiki M, Hattori S, Hirayama Y, and Yoshida M: Human adult Tcell leukemia virus: Complete nucleotide sequence of the provirus genome integrated in leukemia cell DNA. Proc Natl Acad Sci USA 1983;80:3618-3622.

13. Ellerbrok H, Fleischer C, Salemi M, et al:: Sequence analysis of the first HTLV-1 infection in Germany without relations to endemic area. AIDS Res Hum Retroviruses 1998;14:1199-1203.

14. Felsenstein J: Confidence limits on phylogenies: An approach using the bootstrap. Evolution 1985;39:783-791.

Address reprint requests to:

Georg Pauli

Retrovirologie

Robert Koch Institut

Nordufer 20

13353 Berlin, Germany

E-mail:PauliG@rki.de 